\title{
Obliquely Bideposited TiN Thin Film with Morphology-Dependent Optical Properties
}

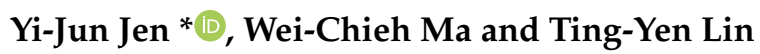 \\ Department of Electro-Optical Engineering, National Taipei University of Technology, Taipei 106, Taiwan; \\ jackiema860704@gmail.com (W.-C.M.); smile090188@gmail.com (T.-Y.L.) \\ * Correspondence: jyjun@ntut.edu.tw
}

check for updates

Citation: Jen, Y.-J.; Ma, W.-C.; Lin, T.-Y. Obliquely Bideposited TiN Thin Film with Morphology-Dependent Optical Properties. Coatings 2021, 11, 1418. https://doi.org/10.3390/ coatings11111418

Academic Editor: Fedor Vasilievich Grigoriev

Received: 16 October 2021 Accepted: 17 November 2021 Published: 20 November 2021

Publisher's Note: MDPI stays neutral with regard to jurisdictional claims in published maps and institutional affiliations.

Copyright: (c) 2021 by the authors. Licensee MDPI, Basel, Switzerland. This article is an open access article distributed under the terms and conditions of the Creative Commons Attribution (CC BY) license (https:// creativecommons.org/licenses/by/ $4.0 /)$.

\begin{abstract}
TiN thin films were obliquely bideposited with different subdeposit thicknesses. The morphology of the bideposited film was varied from a nano-zigzag array to a vertically grown columnar structure by reducing the subdeposit thickness. The principal index of refraction and extinction coefficient were obtained to explain the measured reflectance and transmittance spectra. The loss of the bideposited thin film decreased as the thickness of the subdeposit decreased. The principal indices for normal incidence were near or under unity, indicating the low reflection by the bideposited thin films. A TiN film with a subdeposit thickness of $3 \mathrm{~nm}$ demonstrated an average index of refraction of 0.83 and extinction coefficient of below 0.2 for visible wavelengths. The retrieved principal refractive indexes explained the anisotropic transmission and reflection. For most normal incident cases, the analysis offers the tunable anisotropic property of a TiN nanostructured film for multilayer design in the future.
\end{abstract}

Keywords: titanium nitride; glancing angle deposition; nanostructure; refractive index

\section{Introduction}

Transition metal nitrides (TMNs), such as titanium nitride (TiN) and zirconium nitride $(\mathrm{ZrN})$, are new plasmonic materials that are replacing noble metals in plasmonic applications [1-3]. As well as featuring carrier concentrations and mobilities as high as those of noble metals [4], TMNs feature high melting points and chemical stabilities at temperatures above $2000{ }^{\circ} \mathrm{C}[5,6]$. Conventionally, TMNs with mechanical refraction have been used in hard coatings [7]. Recent works focused on the tunable optical properties of TMN films $[8,9]$. For example, the permittivity of a TiN film that is deposited in a sputtering system can be tuned to be metal-like or dielectric-like by controlling the deposition parameters, including the substrate bias voltage and the nitrogen and argon flow rates [10]. Usually, TiN film displays lossy dielectric properties in visible wavelength ranges and metal-like properties at infrared wavelength ranges. The wavelength-dependent optical property enables TiN to be applied in intermediate components that absorb solar irradiation [11]. Notably, nanostructured TiN films have favorable admittance matching properties. Due to plasmonic effects, TiN nano-square rings [12] are regularly distributed on $\mathrm{SiO}_{2}$ films that are coated on silicon to provide high absorptance for visible wavelengths. Like TiN nanosquare ring arrays, glancing-angle deposited TiN nanorod arrays also exhibit broadband and wide-angle admittance matching [13].

Glancing-angle deposition (GLAD) is a unique form of physical vapor deposition that involves tilting the substrate so that its surface normal makes an angle $\alpha$ with respect to the incident vapors. The initial nucleation of condensed adatoms on a substrate induces self-shadowing, preventing the arrival of the vapor flux at the shadowed area. GLAD is a method for easily fabricating tilted nanorod arrays over large areas. A tilted nanorod array exhibits polarization-dependent reflection and transmission, which limit its range of uses at normal incidence. With one of its three principal axes parallel to nanorod growth [14-16], a tilted nanorod array exhibits complex optical properties at normal incidence, especially 
when its principal refractive indices are complex. Besides tilted nanorod arrays, various dielectric nanostructures can be mass-produced by manipulating the substrate during deposition $[14,17]$. Serial bideposition involves rotating the substrate stepwise by half a turn about its normal during GLAD to grow zigzag nanostructured arrays $[18,19]$. The halfpitch of a zigzag is the thickness of subdeposit, $\mathrm{d}_{\text {sub }}$. When the thickness of subdeposit is close to or less than the rod width, the individual zigzag structure shrinks to a column that is perpendicular to the substrate. The pitch-dependent birefringence of a bideposited $\mathrm{TiO}_{2}$ film [19] was investigated to show that the pitch length was inversely proportional to the birefringence. Figure 1 schematically depicts a nano-zigzag array and system coordinates whose $\mathrm{z}$ axis is normal to the surface and whose $\mathrm{y}-\mathrm{z}$ plane is coincident with the deposition plane that contains the surface normal and the direction of initial deposition flux. When the $d_{\text {sub }}$ is near to or less than the rod width, the equivalent principal axes are coincident with the system coordinates. The principal $\mathrm{z}$ axis is normal to the surface; and the principal $\mathrm{x}$ axis is on the deposition plane that contains the $\mathrm{z}$ and $\mathrm{x}$ axes. For normal incidence, the birefringence $n_{x}-n_{y}$ (the difference between principal indexes $n_{x}$ and $n_{y}$ ) of a bideposited $\mathrm{TiO}_{2}$ film increases as the subdeposit thickness is reduced. The maximum birefringence of a bideposited $\mathrm{TiO}_{2}$ thin film with a pitch length of less than $5 \mathrm{~nm}$ was 0.15 . In another work, a bideposited $\mathrm{Ag}$ film exhibited a negative real index of refraction $\mathrm{n}_{\mathrm{x}}$ and a positive real index of refraction $\mathrm{n}_{\mathrm{y}}$, causing extremely large phase retardation with only a small thickness [20]. Since TiN exhibits dielectric optical properties at visible wavelengths less than the cross-zero wavelength (the wavelength at which the real part of permittivitty is zero) and metal optical property at wavelengths larger than the cross-zero wavelength, it is interesting to study the anisotropic optical property from a bideposited TiN film. On the other hand, a TiN nanorod array can be derived by nitrogenizing a GLAD $\mathrm{TiO}_{2}$ nanorod array [21], which inspired us to observe the anisotropic property of a bideposited TiN film and investigate the influence of deposition parameter on the anisotropy. Furthermore, a bideposited thin film presents two orthogonal principal indexes for normal incident waves, which could benefit multilayer design in the future.

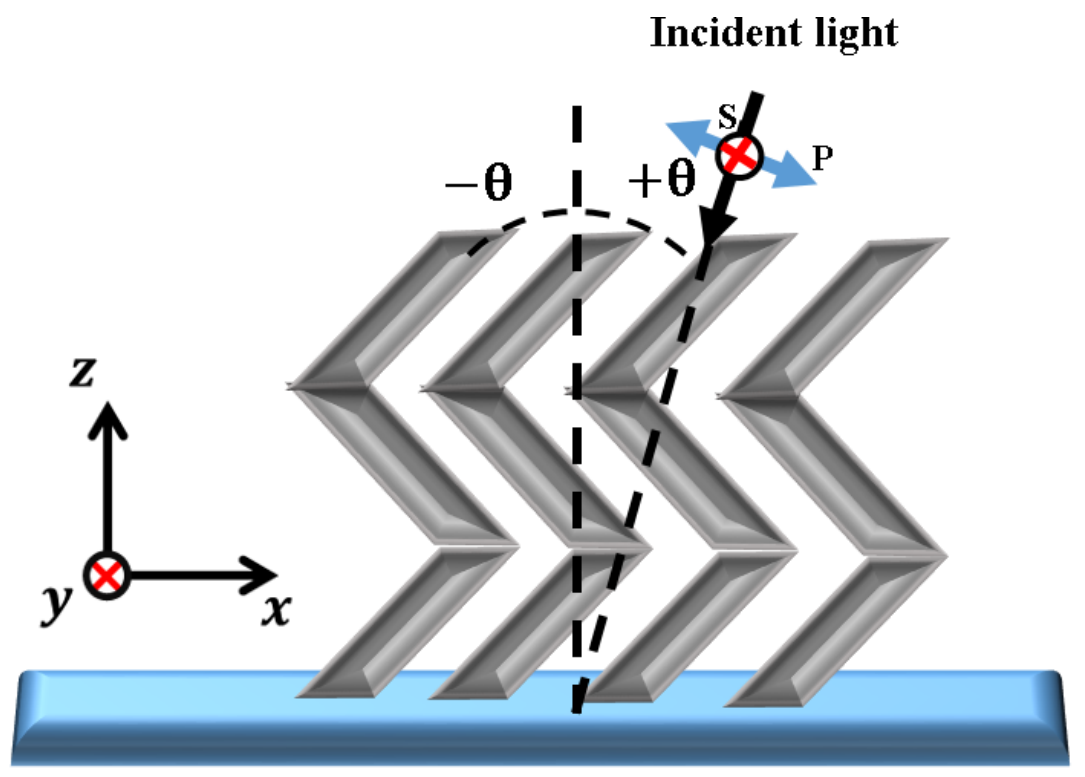

Figure 1. Schematic drawing of a nano-zigzag array. 


\section{Fabrication}

In this study, GLAD was used to bideposit serially TiN nanozigzag arrays with different $d_{\text {sub }}$. The birefringence and two principal indices corresponding to the normal incident wave that varied with subdeposit thickness were investigated. In the fabrication, TiN nanostructured films were deposited on glass substrates in a DC magnetron sputtering system in a prior background vacuum of $4 \times 10^{-6}$ torr at room temperature. The deposition was conducted at a pressure of $4 \times 10^{-3}$ torr with a varying flow rate of nitrogen. A Ti target with a diameter of 3 inches, a thickness of $4 \mathrm{~mm}$, and a purity of $99.99 \%$ was attached to a $\mathrm{Cu}$ plate for sputtering. The deposition rate was controlled using a quartz crystal microbalance and maintained at $0.07 \mathrm{~nm}$ per second; the deposition angle $\theta_{\mathrm{v}}=86^{\circ}$ was the angle between the vertical line and the substrate normal. Sputtered atoms were aligned and the flux was controlled by setting a plate parallel to the substrate [22]. All the films were deposited with a substrate bias of $100 \mathrm{~V}$ and the flow rates of $\mathrm{Ar}$ and $\mathrm{N}_{2}$ were fixed at 15 and $3.5 \mathrm{sccm}$, respectively. The deposition parameters were demonstrated to result in the growth of a metal-like TiN thin film [23]. To determine the actual growth deposition rate of bideposition, a slanted TiN nanorod array (NRA) with a thickness of $90.4 \mathrm{~nm}$ was fabricated by GLAD before bideposition. The thickness growth rate per minute was $0.25 \mathrm{~nm} / \mathrm{min}$ which was obtained from the cross-sectional SEM image for the TiN NRA, as shown in Figure 2a. The thickness of the bideposited film was controlled accordingly. The optical property of a TiN NRA was reported in our previous paper [23]. The TiN NRA in this work was used to discover the growth rate of GLAD. Four TiN bideposited thin films with designed $\mathrm{d}_{\text {sub }}$ of $50,25,12.5,6$ and $3 \mathrm{~nm}$ were fabricated on BK7 glass substrates (I-MEI MATERIALS, Taipei, Taiwan) [24], and denoted as $\operatorname{TiN}_{50}^{3}, \operatorname{TiN}_{25}^{4}, \operatorname{TiN}_{12.5}^{8}, \mathrm{TiN}_{6}^{16}$, and $\mathrm{TiN}_{3}^{32}$, respectively. The superscript in the notation specifies the number of bideposits in the fabrication. BK7 glass is an extremely common crown glass with an index of refraction of 1.52 and a wavelength of $550 \mathrm{~nm}$ [24]. All of the samples except for $\mathrm{TiN}_{50}^{3}$ featured similar thicknesses, around $90.8 \mathrm{~nm}$. Figure 2 presents top-view and cross-sectional SEM images of all the samples. The sample $\mathrm{TiN}_{50}^{3}$ retains the clear zigzag morphology. The mean tilt angle of the rods, measured between the rod and normal to the surface is $24.7^{\circ}$, and the mean rod width is $27 \mathrm{~nm}$. These values are close to those for a slanted TiN nanorod array. For $\mathrm{TiN}_{25}^{4}$, the zigzag morphology is vague and the average width of an individual saw-like column is $56 \mathrm{~nm}$. As the subdeposit thickness was reduced to less than $12.5 \mathrm{~nm}$, the zigzag structure became columnar. The insets displayed in Figure 2 were observed using Image $\mathrm{J}$ [25] to determine the width of the column. The porosity was inversely proportional to the $d_{\text {sub }}$ because the nanorods in the obvious zigzag structures overlapped with each other, as shown in Figure 2. As the dsub reduced, the overlap phenomenon disappeared to leave more space for air. The width of the column decreased from 56 to $47 \mathrm{~nm}$ as $\mathrm{d}_{\text {sub }}$ decreased from 25 to $3 \mathrm{~nm}$. Table 1 shows the width of the nanozigzag, thicknesses, and the deposition time for each sample.

Table 1. The morphology parameters of TiN nano-zigzag deposited at different subdeposit thicknesses.

\begin{tabular}{cccc}
\hline Samples & $\begin{array}{c}\text { Average Width of } \\
\text { Nanozigzag }(\mathbf{n m})\end{array}$ & Thicknesses (nm) & $\begin{array}{c}\text { Deposition Time } \\
\text { (min) }\end{array}$ \\
\hline TiN NRA & 60 & 90.4 & 396 \\
$\operatorname{TiN}_{50}^{3}$ & 66 & 132.52 & 608 \\
$\operatorname{TiN}_{25}^{4}$ & 56 & 91.09 & 408 \\
$\operatorname{TiN}_{12.5}^{8}$ & 53 & 91.45 & 408 \\
$\operatorname{TiN}_{6}^{16}$ & 49 & 91.35 & 408 \\
$\operatorname{TiN}_{3}^{32}$ & 47 & 89.67 & 408 \\
\hline
\end{tabular}



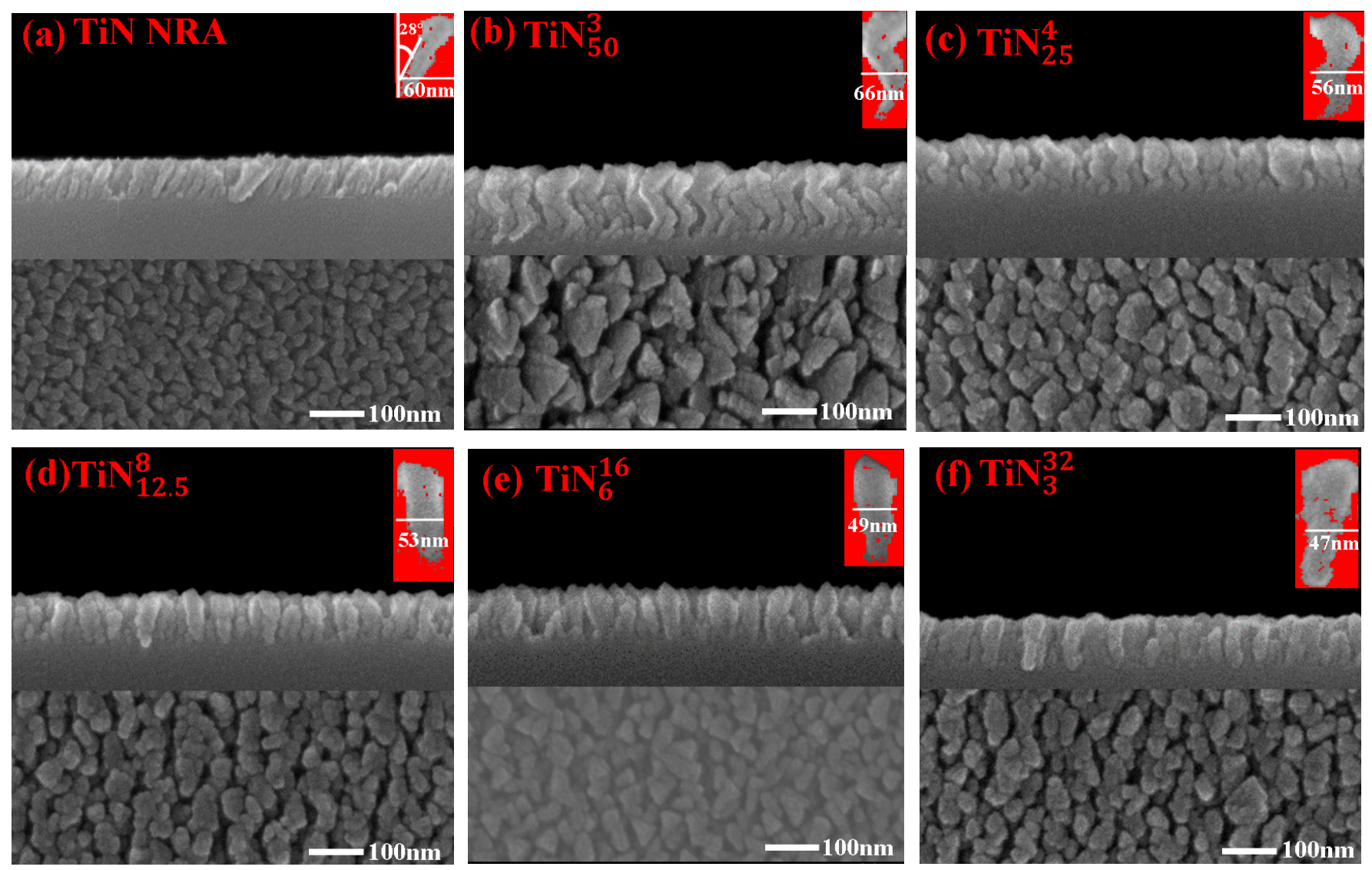

Figure 2. Cross-section and top-view scanning electron microscopic (SEM) images of TiN NRA and bideposited thin films: (a) TiN NRA; (b) $\operatorname{TiN}_{50}^{3} ;$ (c) $\operatorname{TiN}_{25}^{4} ;$ (d) $\operatorname{TiN}_{12.5}^{8} ;$ (e) $\operatorname{TiN}_{6}^{16} ;$ (f) $\operatorname{TiN}_{3}^{32}$.

\section{Measurement and Discussion}

The phase retardation between the x-polarized and y-polarized waves that were transmitted through the film was measured using an ellipsometer (J. A. Woollam Co., M2000, Lincoln, NE, USA). The spectra of phase retardation (PR) of all the samples decayed from a wavelength of 380 to $1680 \mathrm{~nm}$, and were smooth and varied only slightly in the infrared regime, as shown in Figure 3a. Phase retardation can be achieved using a lossless anisotropic thin film with equivalent birefringence $\Delta \mathrm{n}, \Delta \mathrm{n}=\lambda \times \mathrm{PR} /(2 \pi \mathrm{d}) ; \lambda$ is the wavelength in free space, and $d$ is the film thickness. At the shortest wavelength, the bideposited TiN films demonstrated larger equivalent birefringence values than TiN NRA, but its $d_{\text {sub }}$ exhibited no evident trend. However, the birefringence at infrared wavelengths was larger than in the visible regime and inversely proportional to $d_{\text {sub }}$. Figure $3 b$ plots the equivalent birefringence as a function of wavelength. At $d_{\text {sub }}<12.5 \mathrm{~nm}, \Delta \mathrm{n}$ was close to 2.17 at $\lambda=1680 \mathrm{~nm}$.

The reflectance (R) and transmittance (T) spectra of bideposited thin films were measured using a spectrometer (UH4150, Hitachi, Tokyo, Japan), as shown in Figure 4. The extinctance $(\mathrm{E})$ was calculated using the relation $\mathrm{E}=1-\mathrm{R}-\mathrm{T}$. In the measurement, the incident plane was coincident with the deposition plane ( $x-z$ plane). All the films exhibited similar trends of transmittance and reflectance. The p-polarized transmittance exceeded the s-polarized transmittance and the p-polarized reflectance was less than the s-polarized reflectance. The bideposited TiN thin films exhibited a larger polarization-dependent transmittance (reflectance) than did the TiN NRA. The difference between the p-polarized and s-polarized transmittances of the bideposited thin film varied within the range of $10 \%$ to $15 \%$ and that between the p-polarized and s-polarized reflectances varied by less than $5 \%$ over the whole wavelength range. The transmittance increased and the reflectance decreased as $d_{\text {sub }}$ decreased. Because the average width of the nanozigzags was reduced 
by decreasing the $d_{\text {sub }}$, the thinner nanozigzag led to better admittance matching and lower reflectance. The extinction was also improved because the porosity was higher for a sample with lower $d_{\text {sub }}$. The fitting index of refraction and extinction coefficient spectra demonstrated the reasons that caused the trends in Figure 4. The average p-polarized reflectance of sample $\mathrm{TiN}_{3}^{32}$ was below $12.1 \%$ and the average s-polarized reflectance was $16.4 \%$ over the whole wavelength range. Since the low reflection was associated with effective admittance matching, the equivalent principal refractive indexes $N_{x}=n_{x}-i k_{x}$ and $\mathrm{N}_{\mathrm{y}}=\mathrm{n}_{\mathrm{y}}-\mathrm{ik}_{\mathrm{y}}$ were retrieved by fitting both the reflectance and the transmittance spectra. Figure 5 presents the equivalent refractive index spectra of each bideposited sample for both polarizations.

(a)

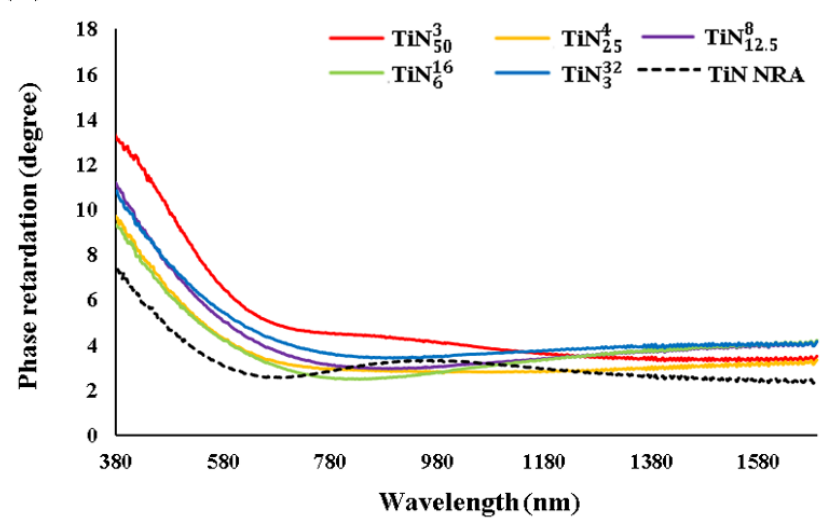

(b)

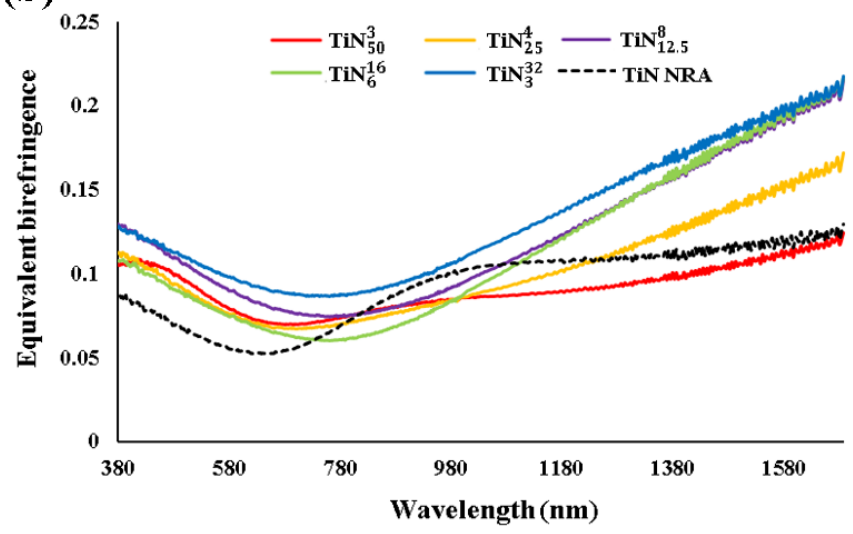

Figure 3. (a) Phase retardation and (b) equivalent birefringence of bideposited TiN films.

The principal index of refraction $n_{x}$ was larger than $n_{y}$ and the extinction coefficient $\mathrm{k}_{\mathrm{x}}$ was less than $\mathrm{k}_{\mathrm{y}}$ for all the samples. In the sample $\mathrm{TiN}_{50}^{3}$, the index of refraction $\mathrm{n}_{\mathrm{y}}$ decreased from 1.23 at $400 \mathrm{~nm}$ to 0.717 at $2000 \mathrm{~nm}$ and the index of refraction $n_{x}$ decreased from 1.326 at $400 \mathrm{~nm}$ to 0.733 at $2000 \mathrm{~nm}$. Both indices $n_{x}$ and $n_{y}$ decreased as $d_{\text {sub }}$ decreased. Therefore, the index of refraction $\mathrm{n}_{\mathrm{y}}$ of $\mathrm{TiN}_{3}^{32}$ decreased from 0.807 at $500 \mathrm{~nm}$ to 0.568 at $1850 \mathrm{~nm}$ and the index of refraction $\mathrm{n}_{\mathrm{x}}$ decreased from 0.905 at $500 \mathrm{~nm}$ to 0.768 at $1850 \mathrm{~nm}$. The extinction coefficient dipped at $\lambda=500 \mathrm{~nm}$ and increased from its minimum with $\lambda$ up to $1700 \mathrm{~nm}$. For the samples with $\mathrm{d}_{\mathrm{sub}}=25,12.5,6$ and $3 \mathrm{~nm}$, the extinction coefficients increased smoothly over the infrared wavelengths. Both indices $\mathrm{k}_{\mathrm{x}}$ and $\mathrm{k}_{\mathrm{y}}$ also decreased as $\mathrm{d}_{\text {sub }}$ decreased. The difference between $\mathrm{k}_{\mathrm{x}}$ and $\mathrm{k}_{\mathrm{y}}$ increased with the wavelength in Figure 5, which was in agreement with the fact that the difference between the s-polarized extinctance and p-polarized extinctance remained similar over the wavelength range in Figure 4. A typical deposited TiN film exhibited metal properties at infrared wavelengths and the magnitude of its negative real permittivity increased with wavelength [23]. Therefore the anisotropic structure caused anisotropic extinction, which increased with the wavelength. For the sample $\mathrm{TiN}_{3}^{32}$, the extinction coefficient $\mathrm{k}_{\mathrm{y}}$ increased from 0.191 at $500 \mathrm{~nm}$ to 0.717 at $1700 \mathrm{~nm}$, and the extinction coefficient $\mathrm{k}_{\mathrm{x}}$ increased from 0.099 at $500 \mathrm{~nm}$ to 0.228 at $850 \mathrm{~nm}$, remaining between 0.22 and 0.26 from 850 to $2000 \mathrm{~nm}$. The extinction coefficients $\mathrm{k}_{\mathrm{x}}$ and $\mathrm{k}_{\mathrm{y}}$ decreased as $\mathrm{d}_{\text {sub }}$ decreased. 
(a)

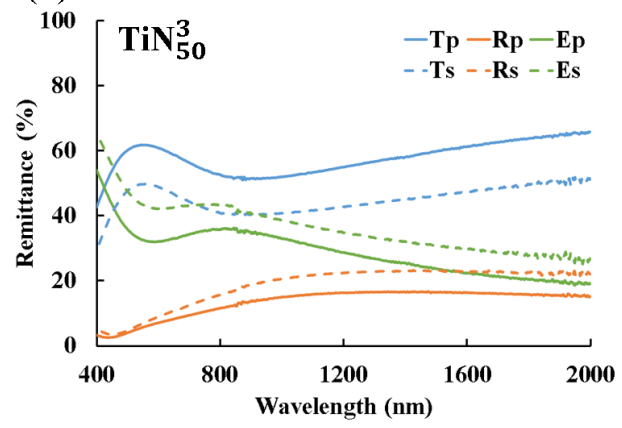

(c)

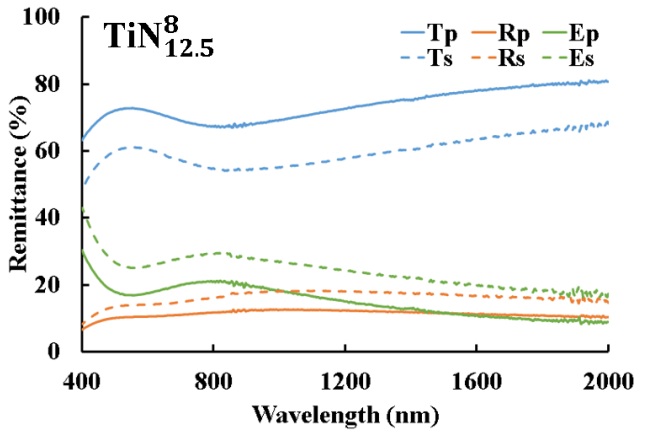

(b)

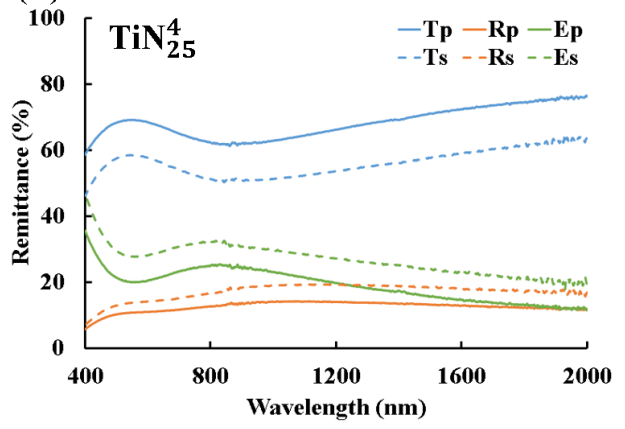

(d)

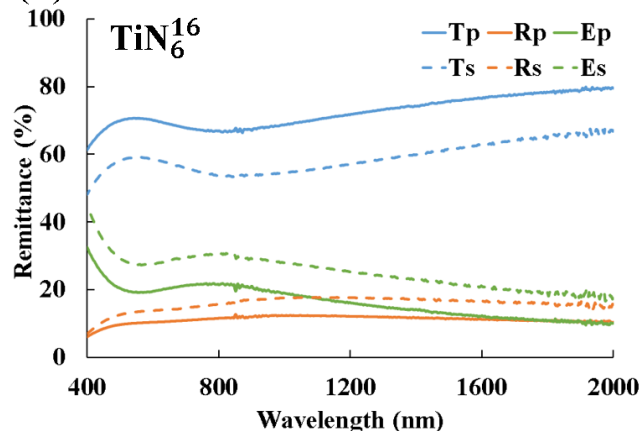

(e)

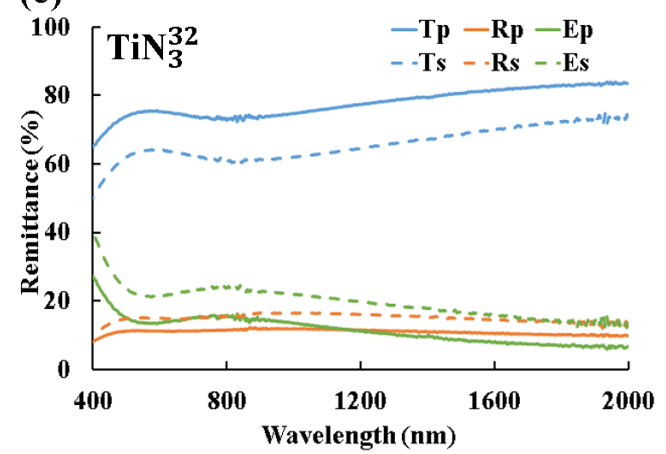

Figure 4. P-polarized and s-polarized transmittance, reflectance, and extinctance spectra measured at normal incidence: (a) $\operatorname{TiN}_{50}^{3} ;$ (b) $\operatorname{TiN}_{25}^{4} ;$ (c) $\operatorname{TiN}_{12.5}^{8}$; (d) $\operatorname{TiN}_{6}^{16}$; (e) $\operatorname{TiN}_{3}^{32}$.

Figures 6-8 plot the measured s-polarized and p-polarized transmittance, reflectance and extinctance spectra versus the angle of incidence from $0^{\circ}$ to $70^{\circ}$, respectively. The results for TiN NRA are similar to those in our previous work. The p-polarized extinctance that corresponded to longitudinal plasmonic resonance reached its maximum at the angle of incidence at which the electric field oscillated along the rods. The p-polarized transmittance was clearly asymmetrical to surface normal for TiN NRA and $\mathrm{TiN}_{3}^{32}$. As $\mathrm{d}_{\text {sub }}$ decreased, the transmittance became symmetrical to surface normal due to the vertical growing columns. The p-polarized reflectance and the s-polarized reflectance were low over all the wavelengths and angles of incidence between $\theta=50^{\circ}$ and $\theta=-50^{\circ}$, which clearly shows admittance matching over wide range of incident angle. For $\mathrm{TiN}_{50}^{3}$, the p-polarized transmittance demonstrated two peaks at $\theta=-60^{\circ}$ and $\theta=70^{\circ}$ at wavelengths over $1600 \mathrm{~nm}$. As $d_{\text {sub }}$ decreased, the area of high transmittance in Figure 6 extended over wide ranges of incident angles and wavelengths. For $\mathrm{TiN}_{3}^{32}$, the p-polarized transmittance exceeded $62.3 \%$ over wavelengths from 400 to $2000 \mathrm{~nm}$ and incident angles from $-50^{\circ}$ to $50^{\circ}$. The bideposited columnar TiN samples $\mathrm{TiN}_{12.5}^{8}, \mathrm{TiN}_{6}^{16}$, and $\mathrm{TiN}_{3}^{32}$ demonstrated their maximum p-polarized extinctance at the largest angles of $\theta=70^{\circ}$ and $\theta=-70^{\circ}$ because the electric field with the largest component oscillated along the columns at the largest 
angles of measurement. This also indicated that the principal refractive index $\mathrm{N}_{\mathrm{z}}$ featured the largest imaginary part $\mathrm{k}_{\mathrm{z}}$ among the three principal refractive indices. The fact that maximum extinctance decays as $d_{\text {sub }}$ decreases indicated that the imaginary part of the principal refractive index $\mathrm{k}_{\mathrm{z}}$ also reduced as $\mathrm{d}_{\text {sub }}$ decreased.

(a)

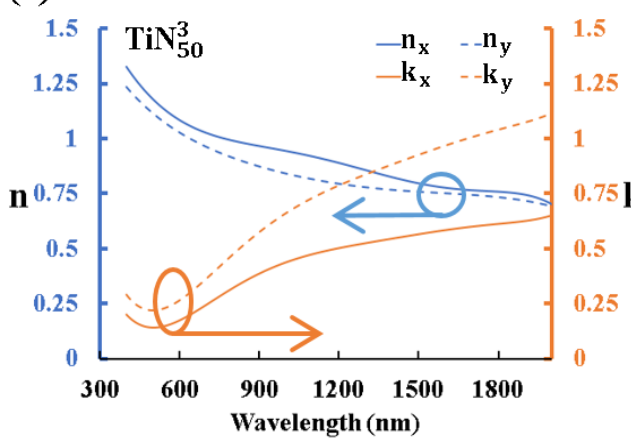

(c)

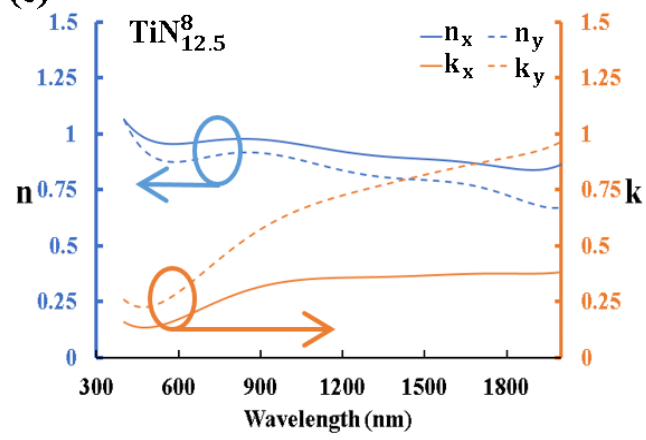

(b)

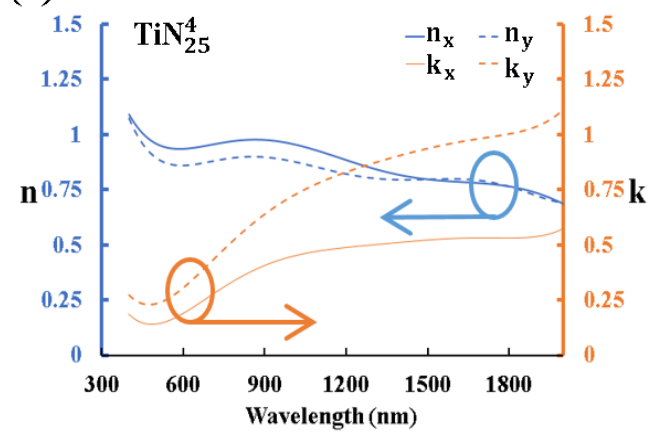

(d)

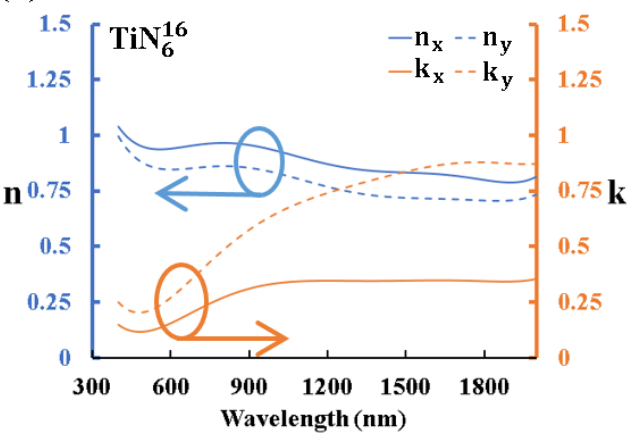

(e)

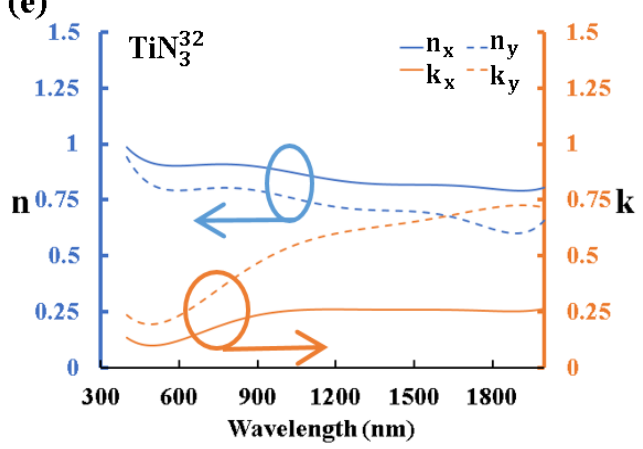

Figure 5. Principal indexes $\mathrm{N}_{\mathrm{x}}=\mathrm{n}_{\mathrm{x}}-\mathrm{ik}_{\mathrm{x}}$ and $\mathrm{N}_{\mathrm{y}}=\mathrm{n}_{\mathrm{y}}-\mathrm{i} \mathrm{k}_{\mathrm{y}}$ of bideposited TiN thin films: (a) $\operatorname{TiN}_{50}^{3}$; (b) $\mathrm{TiN}_{25}^{4} ;$ (c) $\mathrm{TiN}_{12.5}^{8} ;$ (d) $\mathrm{TiN}_{6}^{16} ;$ (e) $\mathrm{TiN}_{3}^{32}$. 
(a)

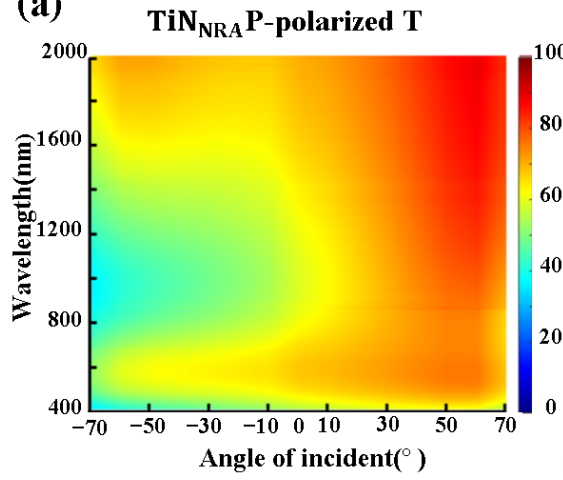

(d)

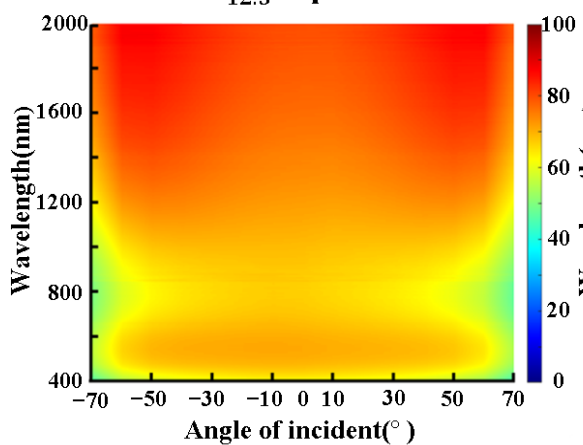

(g) TiN NRA S-polarized T

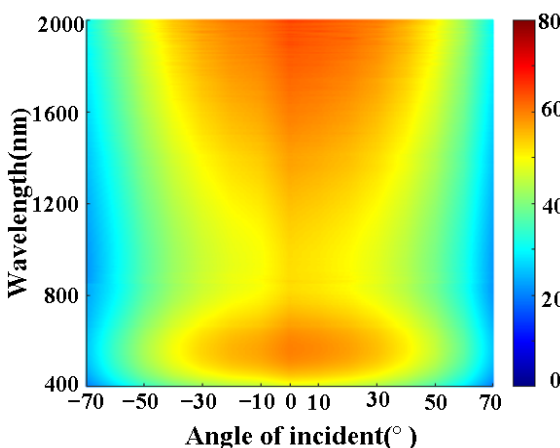

(j) $\quad \mathrm{TiN}_{12.5}^{8} \mathrm{~S}$-polarized $\mathrm{T}$

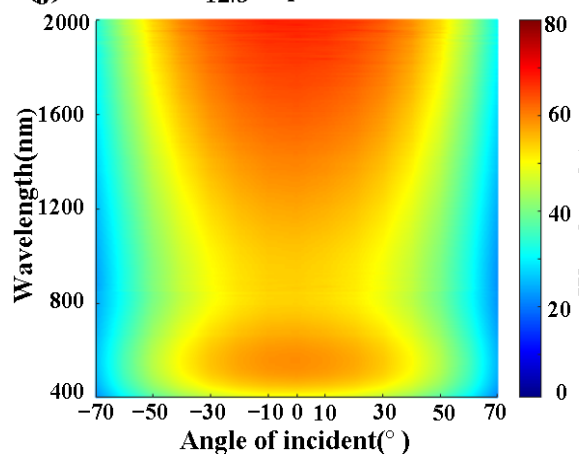

(b) $\quad \operatorname{TiN}_{50}^{3}$ P-polarized T

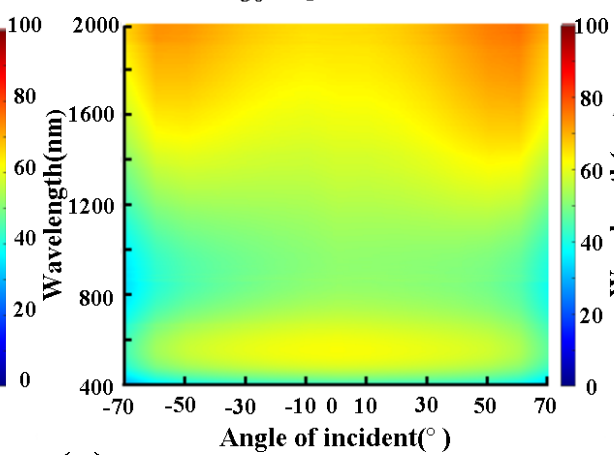

(e) $\quad \mathrm{TiN}_{6}^{16} \mathrm{P}$-polarized $\mathrm{T}$

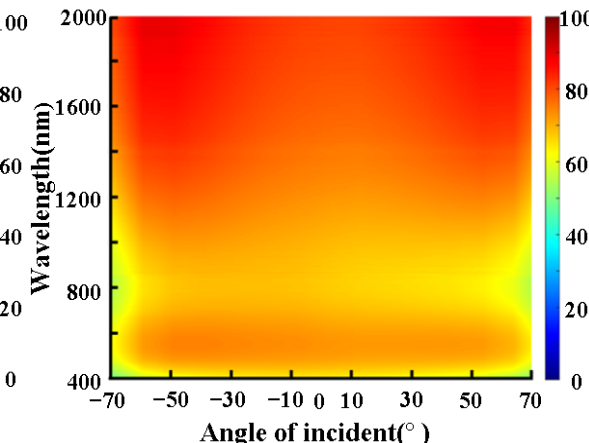

(h) $\quad \mathrm{TiN}_{50}^{3} \mathrm{~S}$-polarized $\mathrm{T}$

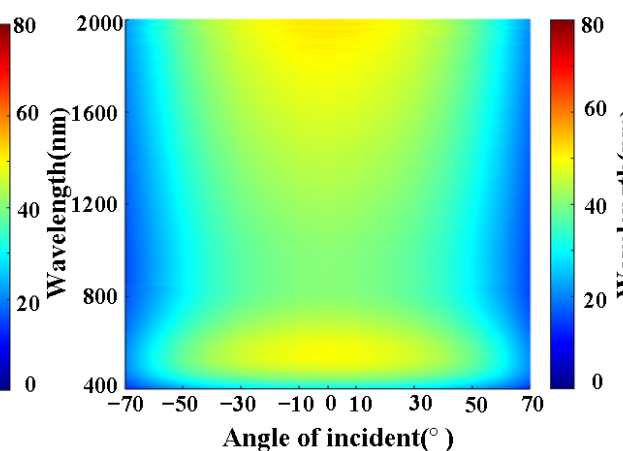

(k) $\quad \mathrm{TiN}_{6}^{16} \mathrm{~S}$-polarized $\mathrm{T}$

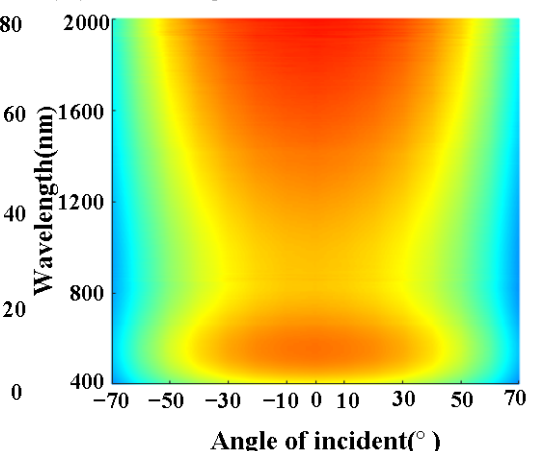

(c) $\quad \mathrm{TiN}_{25}^{4}$ P-polarized T

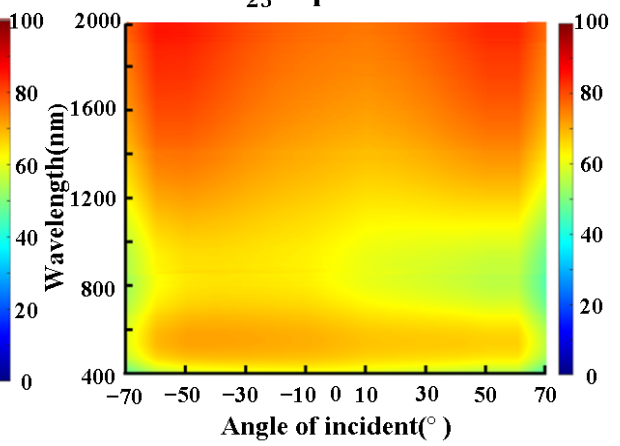

(f) $\quad \mathrm{TiN}_{3}^{32}$ P-polarized $\mathrm{T}$

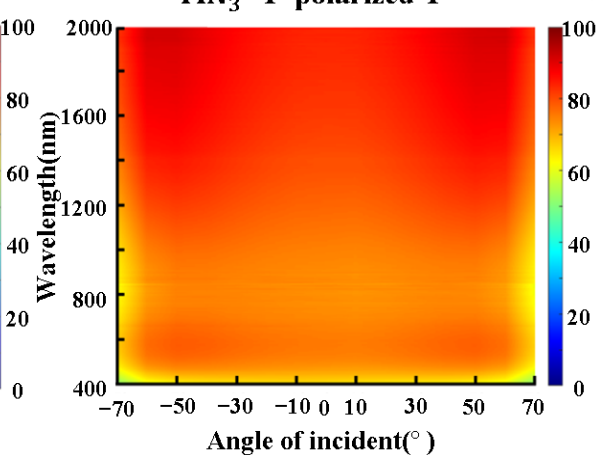

(i) $\quad \mathrm{TiN}_{25}^{4}$ S-polarized $\mathrm{T}$

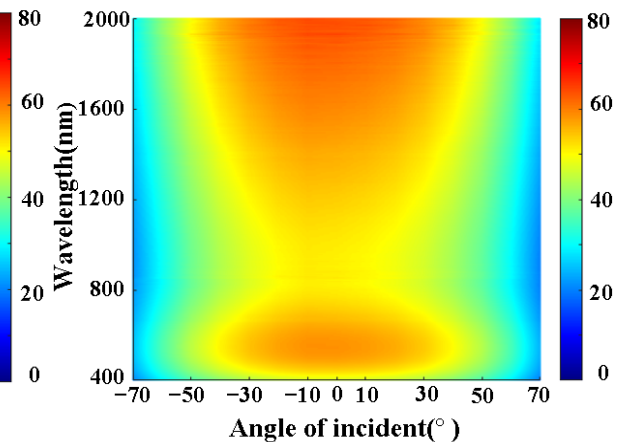

(l) $\quad \mathrm{TiN}_{3}^{32} \mathrm{~S}$-polarized $\mathrm{T}$

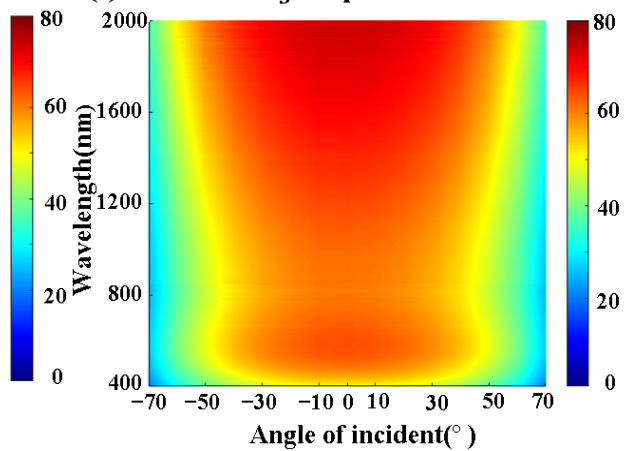

Figure 6. Measured (a-f) p-polarized and (g-l) s-polarized transmittance versus wavelength and angle of incidence of TiN NRA and bideposited TiN films. 
(a) TiN NRA P-polarized $R$

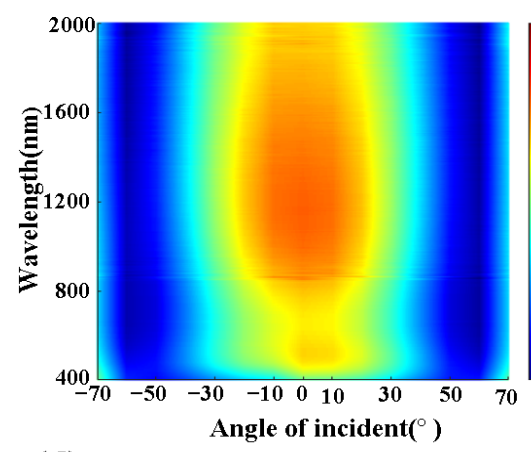

(d) (b)

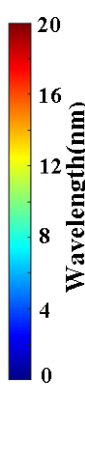

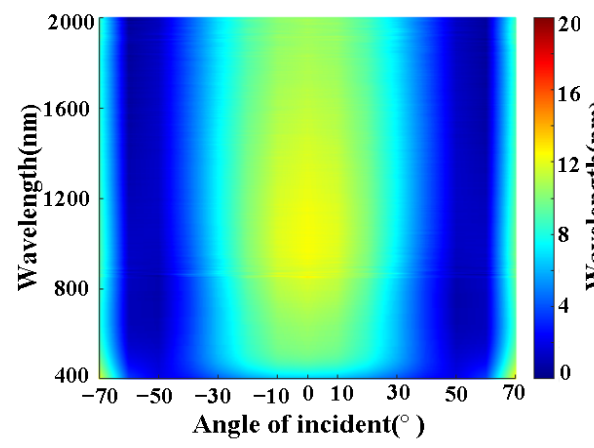

(e)

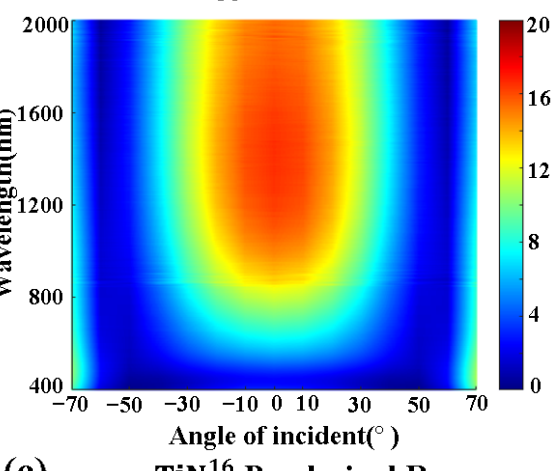

(c)

TiN $_{25}^{4}$ P-polarized R

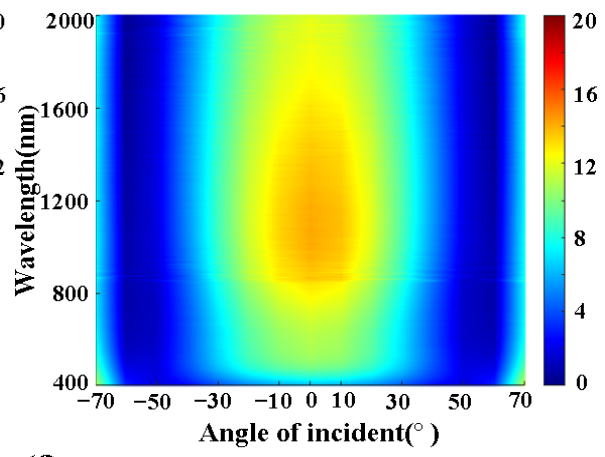

(f)

$\mathbf{T i N}_{3}^{32}$ P-polarized R

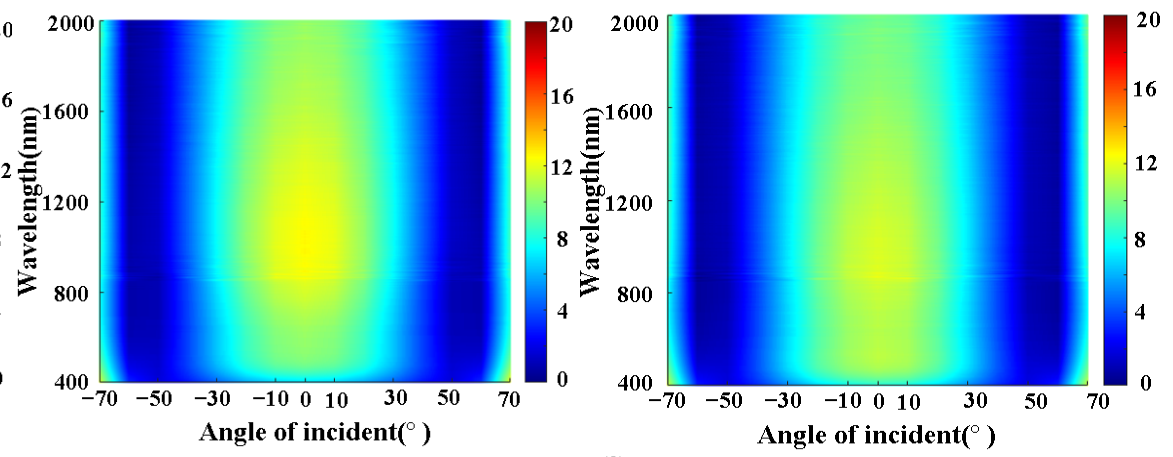

(g) TiN NRA S-polarized R

(h) $\quad \mathrm{TiN}_{50}^{3} \mathrm{~S}$-polarized $\mathrm{R}$

(i)

$\mathrm{TiN}_{25}^{4}$ S-polarized R
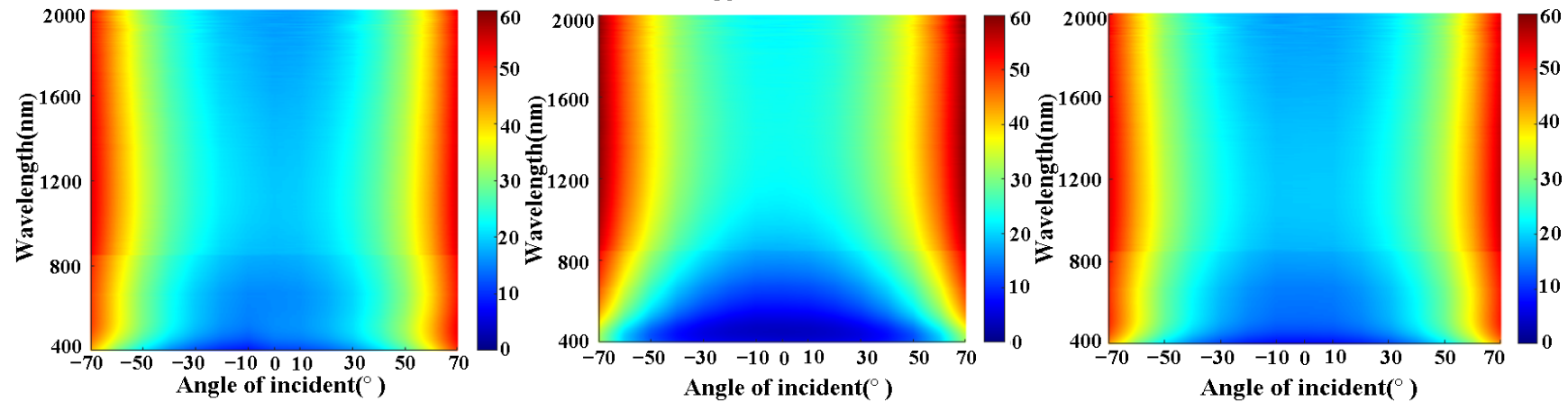

(j) $\quad \mathrm{TiN}_{12.5}^{8} \mathrm{~S}$-polarized $\mathrm{R}$

(k)

(I)

Angle of incident ${ }^{\circ}$ )
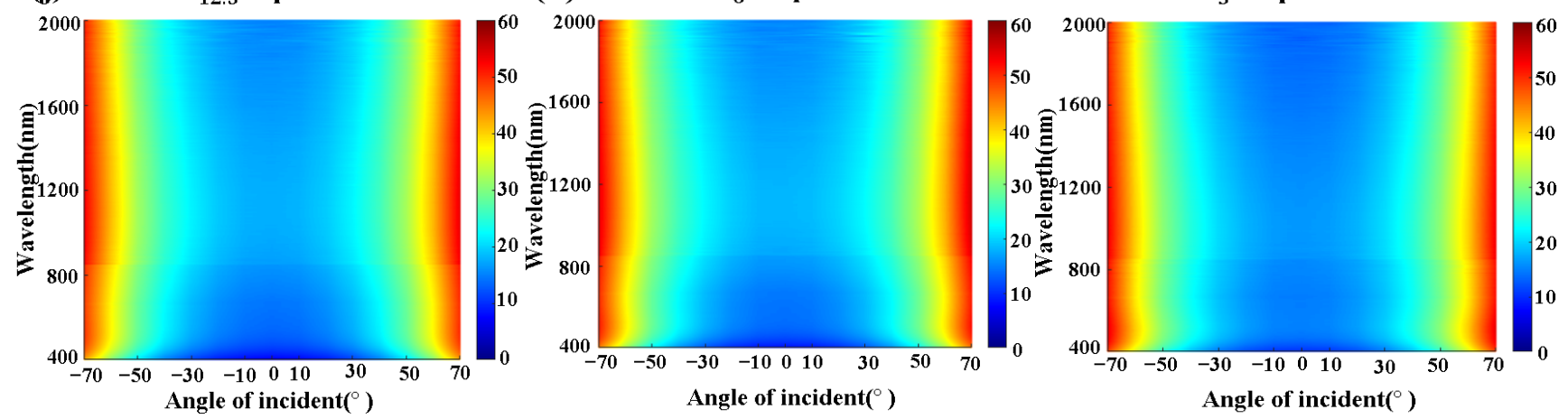

Figure 7. Measured (a-f) p-polarized and (g-l) s-polarized reflectance versus wavelength and angle of incidence of TiN NRA and bideposited TiN films. 
(a) TiN NRA P-polarized E

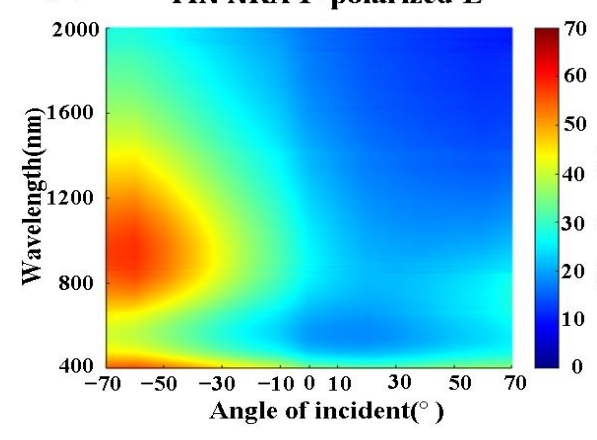

(d) $\quad \mathrm{TiN}_{12.5}^{8} \mathrm{P}$-polarized E

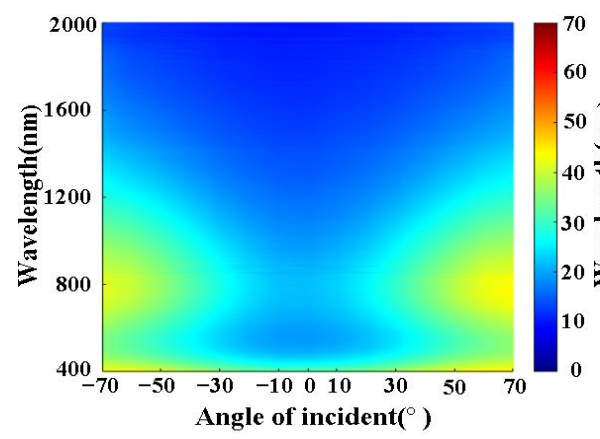

(g)

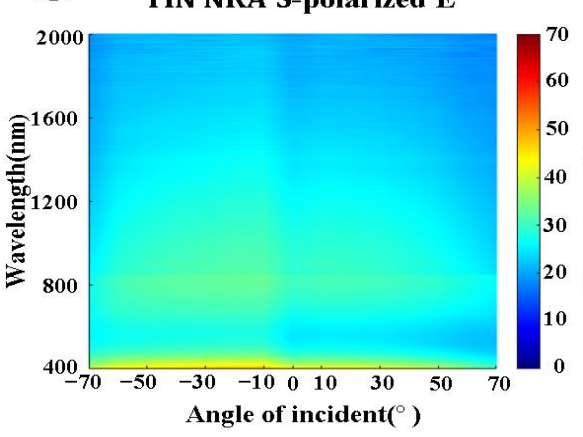

(j)

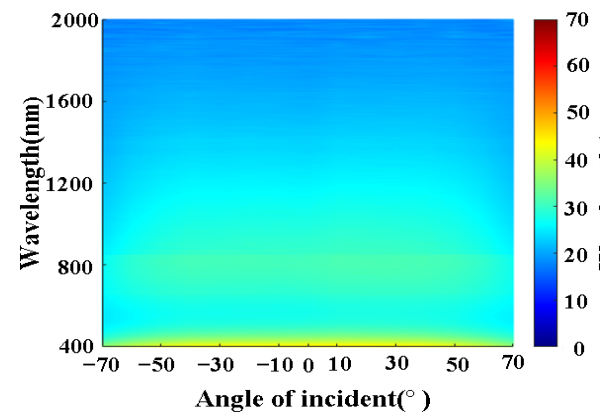

(b)

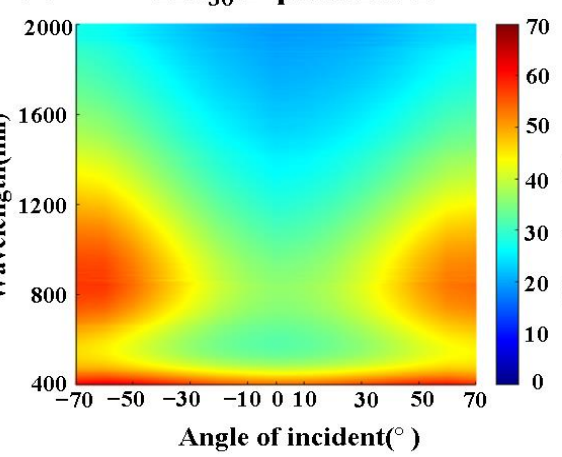

(e) $\operatorname{TiN}_{6}^{16} P$-polarized $E$

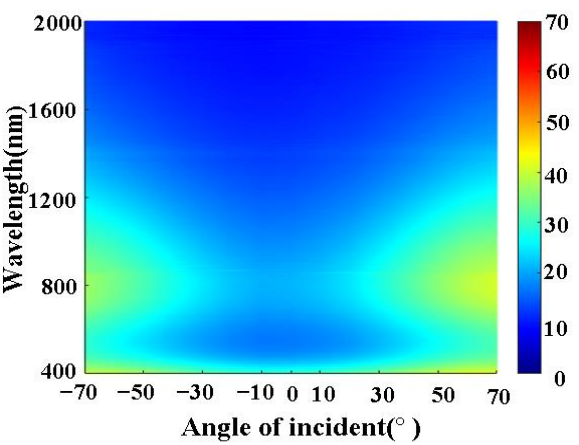

(h) $\operatorname{TiN}_{50}^{3}$ S-polarized $\mathrm{E}$

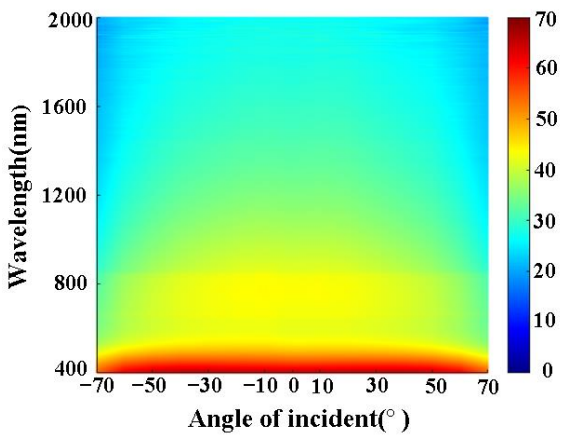

(k)

$\operatorname{TiN}_{6}^{16}$ S-polarized E

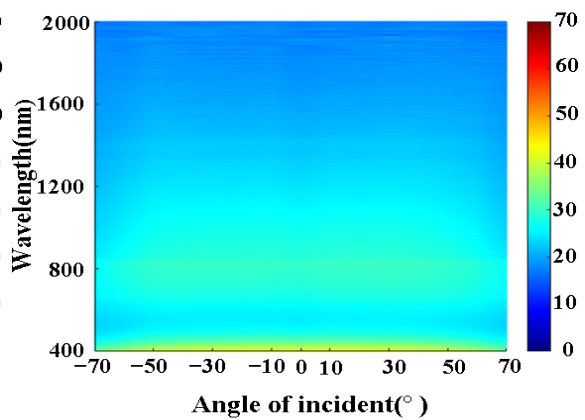

(c) $\quad \mathrm{TiN}_{25}^{4} \mathrm{P}$-polarized E

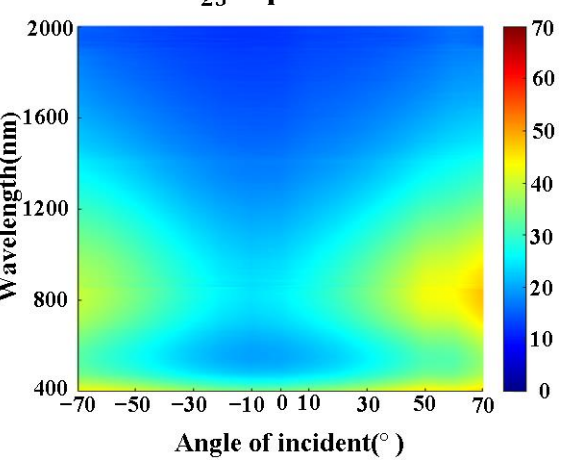

(f)

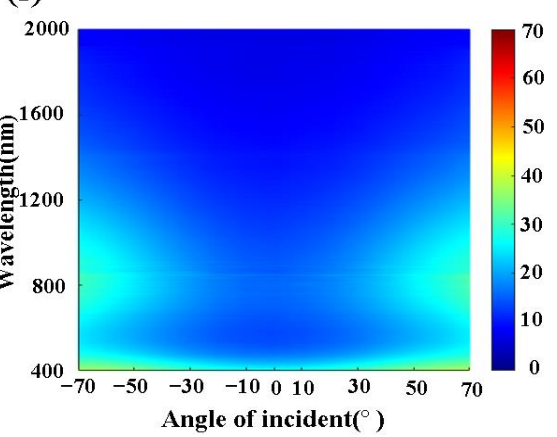

(i)

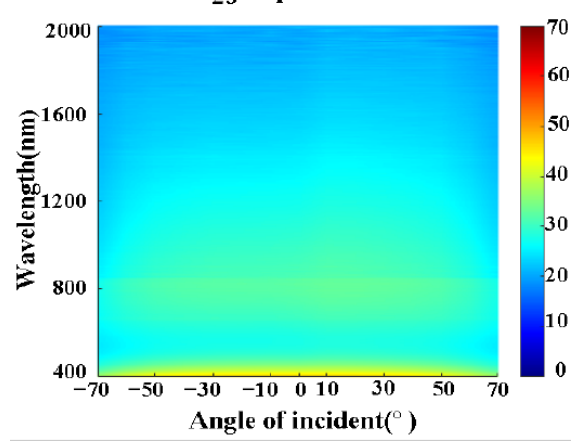

(I)

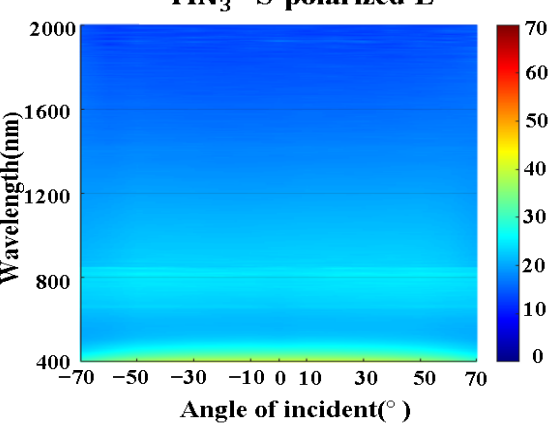

Figure 8. Measured (a-f) p-polarized and (g-l) s-polarized extinctance versus wavelength and angle of incidence of TiN NRA and bideposited TiN films.

\section{Conclusions}

In summary, bideposited TiN films with different subdeposit thicknesses were fabricated to exhibit different optical properties. As well as the deposition parameters, such as reactive gas flow rate, substrate temperature, and deposition rate, the equivalent refractive index could be tuned by varying subdeposit thickness of a bideposited TiN film. The phase retardation values of all the bideposited films varied only slightly with wavelengths over 
$1000 \mathrm{~nm}$, favoring achromatic application in polarization modulation. The bideposited films exhibited low reflection over a broad range of wavelengths and wide range of angles of incidence, indicating that they had favorable admittance matching to air. Most energy of incident light can be coupled into such bideposited thin films efficiently. The bideposited TiN film with a subdeposit thickness of around or less than $12.5 \mathrm{~nm}$ demonstrated a refractive index of approximate unity and a low but unavoidable extinction coefficient in the visible range. A multilayer can be designed and fabricated by alternating bideposited and high-index films to form an edge filter as a thermovoltaic device that performs high absorption in visible wavelength ranges and high reflection in infrared ranges.

Author Contributions: Y.-J.J. conceived the idea and supervised the whole work. W.-C.M. and T.-Y.L. deposited the films and performed measurements. Y.-J.J., W.-C.M. and T.-Y.L. analyzed the data. Y.-J.J. wrote the article. Y.-J.J. and T.-Y.L. revised the paper. All authors have read and agreed to the published version of the manuscript.

Funding: This research was funded by the Ministry of Science and Technology of the Republic of China, Taiwan, for financially supporting this research under contract MOST 108-2221-E -027-100-MY3.

Institutional Review Board Statement: Not applicable.

Informed Consent Statement: Not applicable.

Data Availability Statement: Not applicable.

Conflicts of Interest: The authors declare no conflict of interest.

\section{References}

1. Guler, U.; Shalaev, V.M.; Boltasseva, A. Nanoparticle plasmonics: Going practical with transition metal nitrides. Mater. Today 2015, 18, 227-237. [CrossRef]

2. Korobenko, A.; Saha, S.; Godfrey, A.T.K.; Gertsvolf, M.; Naumov, A.Y.; Villeneuve, D.M.; Boltasseva, A.; Shalaev, V.M.; Corkum, P.B. High-harmonic generation in metallic titanium nitride. Nat. Commun. 2021, 12, 4981. [CrossRef] [PubMed]

3. Zhou, J.; Chen, X.; Guo, L.J. Efficient thermal-light interconversions based on optical topological transition in the metal-dielectric multilayered metamaterials. Adv. Mater. 2016, 28, 3017-3023. [CrossRef] [PubMed]

4. Boltasseva, A.; Atwater, H.A. Low-loss plasmonic metamaterials. Science 2011, 331, 290-291. [CrossRef]

5. Guler, U.; Boltasseva, A.; Shalaev, V.M. Refractory plasmonics. Science 2014, 344, 263-264. [CrossRef]

6. Pogrebnjak, A.; Smyrnova, K.; Bondar, O. Nanocomposite multilayer binary nitride coatings based on transition and refractory metals: Structure and properties. Coatings 2019, 9, 155. [CrossRef]

7. Pierson, H.O. Handbook of Refractory Carbides and Nitrides; William Andrew: Norwich, NY, USA, 1996.

8. Farrell, I.L.; Reeves, R.J.; Preston, A.R.H.; Ludbrook, B.M.; Downes, J.E.; Ruck, B.J.; Durbin, S.M. Tunable electrical and optical properties of hafnium nitride thin films. Appl. Phys. Lett. 2010, 96, 071914. [CrossRef]

9. Hu, C.; Gu, Z.; Wang, J.; Zhang, K.; Zhang, X.; Li, M.; Zhang, S.; Fan, X.; Zheng, W. Nature of tunable optical reflectivity of rocksalt hafnium nitride films. J. Phys. Chem. C 2014, 118, 20511-20520. [CrossRef]

10. Zgrabik, C.M.; Hu, E.L. Optimization of sputtered titanium nitride as a tunable metal for plasmonic applications. Opt. Mater. Express 2015, 5, 2786-2797. [CrossRef]

11. Qin, F.; Chen, X.; Yi, Z.; Yao, W.; Yang, H.; Tang, Y.; Yi, Y.; Li, H.; Yi, Y. Ultra-broadband and wide-angle perfect solar absorber based on TiN nanodisk and Ti thin film structure. Sol. Energy Mater. Sol. C 2020, 211, 110535. [CrossRef]

12. Li, W.; Guler, U.; Kinsey, N.; Naik, G.V.; Boltasseva, A.; Guan, J.; Shalaev, V.M.; Kildishev, A.V. Refractory plasmonics with titanium nitride: Broadband metamaterial absorber. Adv. Mater. 2014, 26, 7959-7965. [CrossRef]

13. Jen, Y.J.; Yang, K.B.; Lin, P.C.; Chung, M.H. Deposited ultra-thin titanium nitride nanorod array as a plasmonic near-perfect light absorber. Sci. Rep. 2020, 10, 22269. [CrossRef] [PubMed]

14. Hodgkinson, I.J.; Wu, Q.H. Birefringent Thin Films and Polarizing Elements; World Scientific Publishing Company: Singapore, 1998.

15. Bairagi, S.; Järrendahl, K.; Eriksson, F.; Hultman, L.; Birch, J.; Hsiao, C.L. Glancing angle deposition and growth mechanism of inclined AlN nanostructures using reactive magnetron sputtering. Coatings 2020, 10, 768. [CrossRef]

16. Martin, P.M. Handbook of Deposition Technologies for Films and Coatings; William Andrew: Norwich, NY, USA, 2010; pp. 621-670.

17. Badshah, M.A.; Koh, N.Y.; Zia, A.W.; Abbas, N.; Zahra, Z.; Saleem, M.W. Recent developments in plasmonic nanostructures for metal enhanced fluorescence-based biosensing. Nanomaterials 2020, 10, 1749. [CrossRef]

18. Park, Y.J.; Sobahan, K.M.A.; Hwangbo, C.K. Optical properties of $\mathrm{TiO}_{2}$ zigzag films prepared by using oblique angle deposition. J. Korean Phys. Soc. 2010, 56, 1378-1381.

19. Hodgkinson, I.; Wu, Q.H. Serial bideposition of anisotropic thin films with enhanced linear birefringence. Appl. Opt. 1999, 38, 3621-3625. [CrossRef] 
20. Jen, Y.J.; Liu, W.C.; Cong, M.Y.; Chan, T.L. Bideposited silver nanocolloid arrays with strong plasmon-induced birefringence for SERS application. Sci. Rep. 2020, 10, 20143. [CrossRef]

21. Guler, U.; Zemlyanov, D.; Kim, J.; Wang, Z.; Chandrasekar, R.; Meng, X.; Stach, E.; Kildishev, A.V.; Shalaev, V.M.; Boltasseva, A. Plasmonic titanium nitride nanostructures via nitridation of nanopatterned titanium dioxide. Adv. Opt. Mater. 2017, 5, 1600717. [CrossRef]

22. Dick, B.; Brett, M.J.; Smy, T.; Belov, M.; Freeman, M.R. Periodic submicrometer structures by sputtering. J. Vac. Sci. Technol. B 2001, 19, 1813. [CrossRef]

23. Jen, Y.J.; Chan, T.L.; Liao, B.H.; Li, Z.X.; Liu, W.C.; Cong, M.Y. Tunable plasmonic resonances in TiN nanorod arrays. Coatings 2019, 9, 863. [CrossRef]

24. Fischer, R.; Galeb, B.T.; Yoder, P. Optical System Design, 2nd ed.; McGraw-Hill Education: New York, NY, USA, 2008.

25. Yadav, J.; Raturi, P.; Yadav, S.; Singh, J.P. Zig-zag $\mathrm{Ag}_{2} \mathrm{~S}$ nanostructures for superior optical absorption and photoelectrochemical water splitting performance. Renew. Energy 2021, 179, 2256-2266. [CrossRef] 